\title{
Metacognição e o ensino e aprendizagem das ciências: uma revisão sistemática da literatura (RSL)
}

Metacognition and the Science Teaching and Learning: a systematic review of literature (RSL)

Maria das Graças Cleophas ${ }^{1}$

Welington Francisco ${ }^{2}$

\section{Resumo}

O objetivo deste artigo é apresentar resultados oriundos de Revisão Sistemática da Literatura (RSL) sobre pesquisas relacionadas ao uso da metacognição na Educação em Ciências. Foram utilizados como fonte de pesquisa vinte periódicos vinculados à área de Ensino das Ciências. Para o levantamento dos dados, foi criado e aplicado o Modelo Sistemático para Pesquisas em Bancos de Dados com Acesso Livre (MSPBAL). Ao todo, foram levantados 76 artigos referentes à temática investigada entre 10.986 trabalhos analisados. Os artigos foram estudados sob dois processos adotados para categorização: 1) aspectos gerais, e 2) dimensão de análise e suas divisões categoriais vinculadas à noção de metacognição. Os resultados apontam que as pesquisas no campo da metacognição são discretas e há necessidade de aprofundamento teórico e empírico, que exibam, por exemplo, resultados de pesquisas utilizando estratégias metacognitivas que demonstrem seus benefícios para a construção do conhecimento dos indivíduos sobre as Ciências Naturais e da avaliação desse conhecimento.

Palavras chave: processos metacognitivos; avaliação metacognitiva; educação em ciências.

\section{Abstract}

The goal of this article is to present results from the Systematic Review of Literature (RSL) on research related to the use of metacognition in Science Education. It was used as research source twenty periodicals linked to the area of Science Teaching. For the data collection, the Systematic Model for Searches in Data Banks with Free Access (MSPBAL) was created and applied. In total, 76 articles were collected regarding the thematic investigated among 10.986 papers analysed. The articles were studied under two processes adopted for categorization: 1) general aspects and 2) dimension of analysis and its category divisions linked to the notion of metacognition. The results indicate that the researches in the field of metacognition are discrete and there is a need for theoretical and empirical deepening, which exhibit, for example, research results using metacognitive strategies that demonstrate their benefits for the construction of individuals' knowledge about the Natural Sciences and evaluation of this knowledge.

Keywords: metacognitive processes; metacognitive evaluation; science education.

\footnotetext{
${ }^{1}$ Universidade Federal da Integração Latino-Americana | maria.porto@unila.edu.br

${ }^{2}$ Universidade Federal da Integração Latino-Americana | welington.francisco@unila.edu.br
} 


\section{Introdução}

A Educação em Ciências na atualidade requer sujeitos que possuam conhecimentos acerca dos procedimentos psicognitivos inerentes aos processos de ensino e aprendizagem. Assim, torna-se efetivamente promissor pensar em estratégias que possam ser usadas por professores e, consequentemente, atividades orientadas para os alunos, visando um autoconhecimento na forma como se ensina e, respectivamente, como se aprende a aprender. Nesse contexto, a metacognição, alinhada à Educação Científica, pode melhorar efetivamente o ensino e aprendizagem das Ciências Naturais.

Em linhas gerais, consideramos que as estratégias metacognitivas devem ser incorporadas por professores e alunos em todos os níveis educacionais. Para os professores, essa incorporação pode ser intencional, desde que ele conheça os benefícios da metacognição, e, para o aluno, ela seria resultado da apreensão metacognitiva do professor com vistas à aprendizagem autorregulada do aluno. Em complemento, Leite e Darsie (2011) asseguram que, quando estas estratégias são aplicadas aos processos de ensino e aprendizagem, elas possuem uma dupla funcionalidade, ou seja, contribuem para melhorar o processo de ensino do professor, como também estimulam o aluno a refletir e a raciocinar sobre os modos pelos quais executa uma atividade ou quando resolve uma dada situação-problema.

É importante considerar que há poucos trabalhos de pesquisa na literatura sobre o desenvolvimento metacognitivo e suas implicações para o ensino e aprendizagem das Ciências Naturais. Porém, é importante considerar que as pesquisas sobre estratégias metacognitivas podem trazer avanços na forma como os sujeitos as ensinam e as aprendem, mostrando, portanto, a necessidade de um maior aprofundamento teórico e aplicacional desse campo de pesquisa na área de Educação em Ciências. Motta (2007, p. 19) defende que existem dois motivos que tornam a metacognição particularmente importante: "primeiro, é uma ferramenta de ampla aplicação em qualquer domínio de operação intelectual; segundo, tem aplicações importantes no campo da educação, como facilitadora da aprendizagem". De modo análogo, Sternberg (2000) enfatiza a importância da metacognição e reitera que ela está centrada na capacidade de as pessoas compreenderem e controlarem seus próprios processos de pensamento, melhorando, assim, a sua aprendizagem. Desta forma, torna-se compreensível que a "essência do processo metacognitivo parece estar no próprio conceito de self, ou seja, na capacidade do ser humano de ter consciência de seus atos e pensamentos" (JOU; SPERB, 2006, p. 177).

Em síntese, uma breve análise sobre a importância da metacognição e sua integração nos processos de ensino e aprendizagem é capaz de evidenciar um quadro teórico e aplicacional que está atrelado a inúmeras ramificações, não menos importantes, sobre a relação da metacognição com a didática das ciências, a citar, como exemplo, as dimensões metacognitivas, os conhecimentos metacognitivos, as estratégias metateóricas (tais como mapas conceituais, diagramas em V, portfólios, avaliação geral, metavisualização, etc.), as competências, entre outras. No entanto, Moreno et al. (1998) alertavam que a metacognição recebia uma atenção limitada pela comunidade investigativa em Didática das Ciências. Assim, impulsionados pela vontade de verificar como a temática vem sendo discutida em um cenário nacional e internacional, estabelecemos, como critério de busca, uma análise em vinte periódicos destinados a divulgar pesquisas sobre Educação em Ciências, propondo, desse modo, revelar um panorama geral sobre estudos relacionados à metacognição. 
Para tanto, este artigo tem como questão norteadora: como estão sendo desenvolvidas as pesquisas sobre metacognição no campo de conhecimento da Educação em Ciências, publicadas em língua portuguesa ou espanhola em bases de dados de acesso aberto? Tivemos, portanto, como objetivo: identificar, analisar, traçar um perfil geral, avanços ou retrocessos e, ainda, verificar se a natureza das pesquisas divulgadas é teórica ou empírica. Feito isso, pretendemos obter condições de levantar aspectos pertinentes às pesquisas envolvendo metacognição, evidenciando, dessa forma, tendências ou lacunas em termos de investigação, que certamente serão importantes para nortear pesquisas futuras.

\section{Metodologia}

A metodologia desta pesquisa é de enfoque qualitativo interpretativo hermenêutico, utilizando uma estratégia de análise documental com foco em uma Revisão Sistemática da Literatura (RSL) (GALVÃO; PEREIRA, 2014). Inicialmente, estabelecemos um objeto de estudo - "Metacognição nos processos de ensino e aprendizagem das Ciências Naturais" - e, posteriormente, uma classificação das informações coletadas durante a RSL, por meio do uso de categorias de análise e organização sistemática sobre as similitudes apresentadas no conjunto de dados obtido. Logo, a ideia principal consiste em compreender a abrangência, peculiaridades e tendências sobre os estudos relacionados à metacognição.

Desse modo, propusemos um modelo dividido em cinco etapas, o qual denominamos de Modelo Sistemático para Pesquisas em Bancos de Dados com Acesso Livre (MSPBAL). A Figura 1 ilustra, resumidamente, os elementos que compõem cada uma das etapas do modelo proposto.

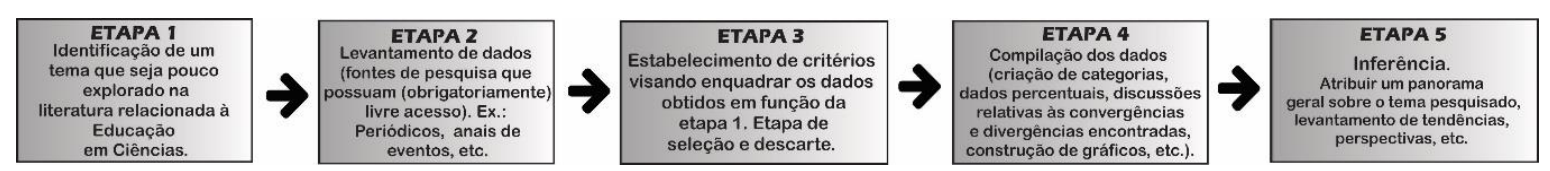

Figura 1: Levantamento de dados utilizando MSPBAL proposto e aplicado nesta pesquisa.

As etapas podem ser descritas da seguinte forma: [1] nesta etapa, foram identificados e definidos um objeto de investigação que tivesse relevância na área de Educação em Ciências, o conjunto de palavras-chave, escolha das fontes de pesquisa (artigos, trabalhos completos apresentados em eventos, resumos expandidos etc.) e elaboração da questão (ou questões) de investigação e objetivos; [2] Busca dos dados em fontes de acesso livre; [3] Aplicação dos critérios para selecionar materiais (dados) que tivessem relação direta com o objeto de investigação descrito na etapa 1. Nesta etapa, visando obter informações, foram utilizadas algumas técnicas de leitura, a citar: leitura exploratória (leitura rápida visando identificar dados que tenham relação direta com o objeto de estudo), leitura seletiva (leitura mais apurada que permite selecionar ou descartar o material coletado), leitura crítica (visando sumarizar as informações coletadas) e, por fim, leitura interpretativa (tendo como objetivo estabelecer relações entre os dados coletados, as possíveis hipóteses elaboradas, a questão de investigação e os objetivos da pesquisa) (SALVADOR, 1986); [4] Nesta etapa ocorreu a compilação dos dados e a elaboração ou adaptação de categorias de análise para agrupar os dados já definitivamente selecionados, construção de gráficos, demais recursos que pudessem explorar e sistematizar os dados levantados; finalmente, a etapa [5], que consistiu na inferência. Nesta etapa, o pesquisador deve apresentar uma compreensão 
sintética sobre o tema de investigação (objeto de estudo), apresentando as tendências relacionadas, implicações, carências em termos de pesquisa para fortalecer o assunto escolhido etc.

Cabe relatar que nesta pesquisa optamos por elaborar categorias de análise, tomando como base dois estudos conexos à metacognição. Logo, o conjunto de unidades codificadas por similitudes atribuídas em uma dada categoria foi fundamentado na Análise de Conteúdo de Bardin (2011). Efetivamente, os artigos selecionados tiveram seus resultados sistematizados em aspectos gerais observados sobre os artigos e categorizados em função de uma Dimensão de Análise e sua subdivisão categorial. O Quadro 1 exibe as dimensões de análise, as categorias definidas e uma breve descrição sobre cada uma delas.

Quadro 1: Dimensão de Análise e suas subdivisões categoriais vinculadas à noção de metacognição.

\begin{tabular}{|c|c|c|}
\hline DIMENSÃO DE ANÁLISE & Categorias de Análise & Breve descrição de cada categoria \\
\hline \multirow{4}{*}{$\begin{array}{l}\text { Processos Metacognitivos } \\
\text { e didática das ciências } \\
\text { (baseado no estudo de } \\
\text { TOVAR-GÁLVEZ, 2012) }\end{array}$} & Resolução de Problemas (RP) & $\begin{array}{l}\text { Considera importante ensinar tanto os } \\
\text { aspectos conceituais da Ciência como } \\
\text { ensinar a proposição de soluções de } \\
\text { situações-problemas. }\end{array}$ \\
\hline & $\begin{array}{c}\text { Aprendizagem por Investigação } \\
\text { Dirigida (AID) }\end{array}$ & $\begin{array}{l}\text { Surge dos fundamentos da RP, } \\
\text { aprofundando nos processos de } \\
\text { construção de conhecimentos científicos } \\
\text { por meio de processo de investigação. }\end{array}$ \\
\hline & $\begin{array}{c}\text { Enfoque Ciência, Tecnologia e } \\
\text { Sociedade (CTS) }\end{array}$ & $\begin{array}{l}\text { Esta perspectiva busca a formação dos } \\
\text { cidadãos mediante a relação entre os } \\
\text { conhecimentos científicos e tecnológicos } \\
\text { e as condições sociais, políticas, } \\
\text { econômicas e ambientais. }\end{array}$ \\
\hline & $\begin{array}{l}\text { Integração entre Didática e } \\
\text { Metacognição (IDM) }\end{array}$ & $\begin{array}{c}\text { Relaciona-se com a reflexão das } \\
\text { estruturas conceituais iniciais, } \\
\text { administração dos conhecimentos, } \\
\text { avaliação das estratégias executadas e do } \\
\text { processo total. }\end{array}$ \\
\hline $\begin{array}{l}\text { Metacognição em relação } \\
\text { à visualização (adaptado } \\
\text { das pesquisas de } \\
\text { LOCATELLI, 2014) }\end{array}$ & Metavisual & $\begin{array}{c}\text { Refere-se à construção de imagens } \\
\text { mentais ou escritas sobre determinando } \\
\text { assunto, tema ou teoria. }\end{array}$ \\
\hline \multirow{3}{*}{$\begin{array}{l}\text { Uso da avaliação como } \\
\text { instrumento metacognitivo } \\
\text { (adaptado do estudo de } \\
\text { CAMPANARIO, 2000) }\end{array}$} & $\begin{array}{l}\text { Retomada de Atividades e } \\
\text { Detecção de Avanços (RADA) }\end{array}$ & $\begin{array}{c}\text { Envolve a análise de atividades realizadas } \\
\text { com os alunos para prover avanços } \\
\text { conceituais posteriores. }\end{array}$ \\
\hline & $\begin{array}{l}\text { Correções e Comentários do(a) } \\
\text { Professor(a) sobre os } \\
\text { Erros/dificuldades (CCPE) }\end{array}$ & $\begin{array}{l}\text { Abrange as orientações feitas pelo } \\
\text { professor para a reflexão dos estudantes. }\end{array}$ \\
\hline & $\begin{array}{l}\text { Aplicação dos Conhecimentos em } \\
\text { Diferentes Situações (ACDS) }\end{array}$ & $\begin{array}{c}\text { Acena para a extrapolação dos } \\
\text { conhecimentos adquiridos em situações } \\
\text { diferenciadas. }\end{array}$ \\
\hline
\end{tabular}




\section{Resultados e discussão}

Os resultados são apresentados em dois momentos distintos. No primeiro são mostrados aspectos gerais dos artigos selecionados, incluindo informações dos periódicos de publicação, área de conhecimentos, nível educacional, tipo de abordagem e nacionalidade dos respectivos autores. Enquanto, no segundo momento, exibe-se a distribuição dos artigos frente a duas abordagens metodológicas (divididas, respectivamente, em Dimensão de Análise e suas subdivisões categoriais), vinculadas à noção de metacognição:

Processos Metacognitivos - são processos que permitem ao docente identificar e avaliar as melhores estratégias didáticas capazes de promover uma aprendizagem mais duradoura e que levem a resultados mais eficazes durante sua ação didático-pedagógica (TOVAR-GÁLVEZ, 2015).

Avaliação como Instrumento Metacognitivo - relaciona-se com diversas atividades de ensino que fomentem tanto a aprendizagem conceitual como a reflexão de como essa aprendizagem aconteceu (CAMPANARIO, 2000).

\section{Aspectos gerais dos artigos selecionados}

Após uma pesquisa exploratória em cerca de 10.986 artigos, distribuídos não uniformemente nos periódicos elencados, encontramos apenas 76 artigos que convergiam com a temática da pesquisa, o que equivale a 0,59\% do total. Este dado é muito importante, pois demonstra que as pesquisas sobre metacognição são bastante incipientes. Ademais, chamou atenção o quantitativo de artigos publicados na revista Enseñanza de las Ciencias e Revista Electrónica de Enseñanza de las Ciencias, muito superior quando comparado aos periódicos nacionais, como apresentado no Gráfico 1.

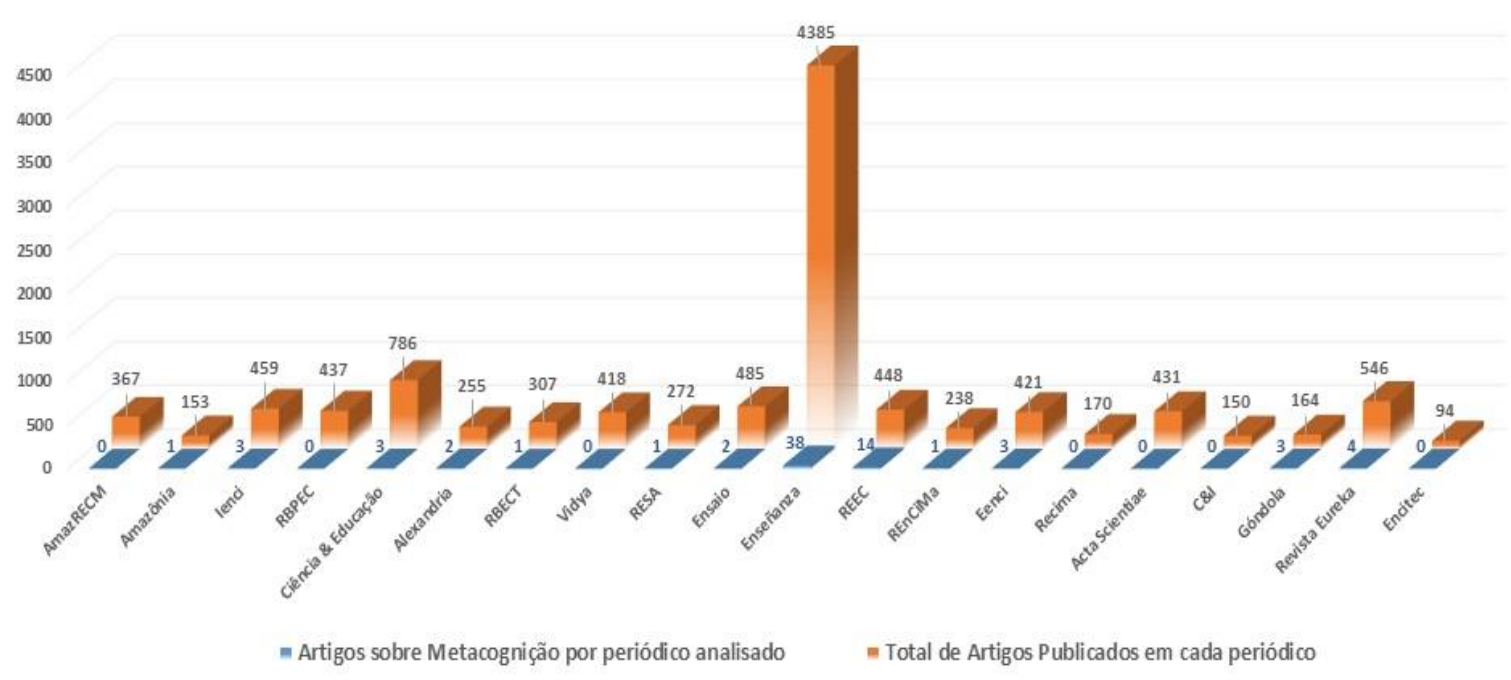

Gráfico 1: Quantitativo de artigos que coadunam com a pesquisa e o número de artigos totais.

Os dados do Gráfico 1 evidenciam que a revista Enseñanza de las Ciencias tem a maior quantidade de publicações quando comparada às demais (4.385). Cabe destacar que, deste total de artigos, 2.814 compreendem artigos publicados em números extras, fruto da compilação de trabalhos apresentados no Congreso Internacional sobre Investigación en la 
Didáctica de las Ciencias (um evento internacional e quadrienal) e, posteriormente, publicados em formato de artigos. Considerando apenas o universo desta revista, foram encontrados 38 artigos atrelados à metacognição, sendo que 21 são artigos pertencentes aos números extras, ou seja, representam $55,26 \%$ do montante encontrado neste periódico.

Tabela 1: Informações dos periódicos e quantidade de artigos selecionados com a temática de metacognição.

\begin{tabular}{|c|c|c|c|c|c|c|c|}
\hline$\#$ & Periódico & Sigla & $\begin{array}{c}\text { Qualis/ } \\
\text { Ensino* } \\
\star\end{array}$ & $\begin{array}{c}\text { Ano que } \\
\text { iniciou as } \\
\text { publicações }\end{array}$ & $\begin{array}{l}\text { Periodi- } \\
\text { cidade/ } \\
\text { ano }\end{array}$ & $\begin{array}{c}\text { Artigos } \\
\text { selecio- } \\
\text { nados }\end{array}$ & $\begin{array}{c}\text { Ano de } \\
\text { publicação } \\
\text { (quantidade } \\
\text { de artigos) }\end{array}$ \\
\hline 1 & $\begin{array}{c}\text { Acta Scientiae: Revista de Ensino } \\
\text { de Ciências e Matemática }\end{array}$ & Acta Scientiae* & A2 & 1999 & 2 & 0 & - \\
\hline 2 & $\begin{array}{c}\text { Alexandria: Revista de Educação } \\
\text { em Ciência e Tecnologia }\end{array}$ & Alexandria* & $A 2$ & 2008 & 2 & 2 & $2014 ; 2017$ \\
\hline 3 & $\begin{array}{c}\text { Amazônia: Revista de Educação } \\
\text { em Ciências e Matemáticas }\end{array}$ & Amaz RECM* & A2 & 2005 & 2 & 1 & 2016 \\
\hline 4 & $\begin{array}{c}\text { Areté: Revista Amazônica de } \\
\text { Ensino de Ciências }\end{array}$ & Areté* & $A 2$ & 2008 & 3 & 0 & - \\
\hline 5 & Ciências \& Educação, Bauru & $\begin{array}{l}\text { Ciência \& } \\
\text { Educação* }\end{array}$ & A1 & 1995 & 3 & 3 & 2009; 2012; 2014 \\
\hline 6 & $\begin{array}{c}\text { Ensaio: Pesquisa em Educação } \\
\text { em Ciências }\end{array}$ & Ensaio* & $A 2$ & 2003 & 2 & 2 & $2013 ; 2016$ \\
\hline 7 & Enseñanza de las Ciencias & Enseñanza & $\mathrm{A} 1$ & 1983 & 3 & 38 & $\begin{array}{c}2003(2) ; 2004 ; \\
2005(7) ; 2006 ; \\
2007(2) ; 2008 ; \\
2009(8) ; 2013 \\
(10) ; 2014(2) ; \\
2015 ; 2016 ; 2017 \\
(2)\end{array}$ \\
\hline 8 & $\begin{array}{l}\text { Ensino de Ciências e Tecnologia } \\
\text { em Revista }\end{array}$ & Encitec $^{*}$ & B1 & 2011 & 2 & 0 & - \\
\hline 9 & $\begin{array}{c}\text { Experiências em Ensino de } \\
\text { Ciências }\end{array}$ & Eenci & B1 & 2006 & 3 & 3 & $2013 ; 2016 ; 2017$ \\
\hline 10 & $\begin{array}{c}\text { Góndola: Enseñanza y } \\
\text { Aprendizaje de las Ciencias }\end{array}$ & Góndola & B1 & 2006 & 2 & 3 & 2010; 2014; 2017 \\
\hline 11 & $\begin{array}{c}\text { Investigações em Ensino de } \\
\text { Ciências }\end{array}$ & lenci & A2 & 1996 & 3 & 3 & $2012 ; 2017$ (2) \\
\hline 12 & $\begin{array}{c}\text { Revista Brasileira de Ensino de } \\
\text { Ciência e Tecnologia }\end{array}$ & RBECT* & $A 2$ & 2008 & 3 & 1 & 2015 \\
\hline 13 & $\begin{array}{c}\text { Revista Brasileira de Pesquisa em } \\
\text { Educação em Ciências }\end{array}$ & RBPEC & A2 & 2001 & 3 & 0 & - \\
\hline 14 & Revista Ciências \& Ideias & $C \& l^{*}$ & B1 & 2009 & 3 & 0 & - \\
\hline 15 & $\begin{array}{c}\text { Revista de Educação, Ciências e } \\
\text { Matemática }\end{array}$ & Recima* & A2 & 2011 & 3 & 0 & - \\
\hline 16 & $\begin{array}{c}\text { Revista de Ensino de Ciências e } \\
\text { Matemática }\end{array}$ & RenCiMa* & $A 2$ & 2010 & 3 & 1 & 2012 \\
\hline 17 & $\begin{array}{c}\text { Revista Ensino, Saúde e } \\
\text { Ambiente }\end{array}$ & RESA* & A2 & 2009 & 3 & 1 & 2014 \\
\hline 18 & $\begin{array}{c}\text { Revista Electrónica de } \\
\text { Enseñanza de las Ciencias }\end{array}$ & REEC & $\mathrm{A} 1$ & 2002 & 3 & 14 & $\begin{array}{c}2005(2) ; 2006 ; \\
2007 ; 2009 ; \\
2010 ; 2011(4) ; \\
2012 ; 2014 ; 2016 ; \\
2017\end{array}$ \\
\hline 19 & $\begin{array}{c}\text { Revista Eureka sobre Enseñanza } \\
\text { y Divulgación de las Ciencias }\end{array}$ & Revista Eureka & $\mathrm{A} 1$ & 2004 & 3 & 4 & $\begin{array}{c}2014 ; 2015 ; 2016 ; \\
2017\end{array}$ \\
\hline 20 & Vidya & Vidya & $\mathrm{A} 2$ & 1976 & 2 & 0 & - \\
\hline
\end{tabular}

*Vinculadas a programas de pós-graduação. **Classificação de acordo com o quadriênio 2013-2016. (Link de acesso: https://sucupira.capes.gov.br). 
Além disso, o levantamento desta pesquisa mostra que as primeiras publicações sobre a temática relacionada à metacognição aconteceram a partir do ano de 2003. Este fato é bastante diagnóstico, porque nos apresenta indícios sobre o interesse de pesquisadores pelo tema metacognição e sua relação com o Ensino de Ciências. Neste viés, Portilho e Dreher (2012) nos revelam que o conceito de metacognição surgiu nos Estados Unidos no início da década de 1970, sendo cunhado pelo psicólogo John Hurley Flavell, o que comprova uma lacuna temporal de mais de 30 anos sem que houvesse produção científica sobre metacognição em Ensino de Ciências (com base nos periódicos analisados).

Ao todo, os periódicos brasileiros divulgaram dezessete artigos, enquanto os internacionais apresentaram cinquenta e nove publicações, mesmo tendo periodicidades e inícios de publicações semelhantes (Tabela 1). Outra informação relevante é o fato de mais da metade dos periódicos selecionados (12) estar vinculada a Programas de Pós-Graduação no Brasil. Uma análise interna destes periódicos mostrou que a publicação de artigos sobre metacognição com foco em Ensino de Ciências representa apenas 0,14\% (11) do total. Apesar de uma inferência precoce, tais resultados indicam que não existem ainda linhas de pesquisas consolidadas em metacognição e, nem tampouco, interesse pelo avanço das discussões teóricas sobre a temática, sendo os trabalhos publicados de forma esporádica e distribuídos entre diferentes revistas e autores. Embora Glaser (1994) destaque que a metacognição é uma das áreas de investigação que mais contribui com a configuração de novas concepções de aprendizagem e ensino, nossos resultados mostram um caminho oposto a esta observação.

Quanto às áreas de conhecimento, os artigos voltados para o Ensino de Biologia se apresentaram em menor porção quando comparados com os de Física e Química, uma vez que estavam mais bem distribuídos entre as revistas. Isso mostra que ainda há uma necessidade de explorar mais a noção de metacognição no ensino e aprendizagem na área de Ciências, principalmente em Biologia (Tabela 2). Entretanto, vale destacar que, nos trabalhos generalizados como "Ciência", as abordagens eram multidisciplinares, na sua maioria, e, em alguns casos, interdisciplinares e contextualizadas.

Tabela 2: Relação quantitativa dos artigos selecionados em diferentes áreas da Ciência e nível escolar.

\begin{tabular}{|c|c|c|c|c|c|c|c|}
\hline \multirow{2}{*}{ Periódico } & \multicolumn{4}{|c|}{ Área de conhecimento } & \multicolumn{3}{c|}{ Nível educacional } \\
\cline { 2 - 9 } & Biologia & Física & Química & Ciências & Fundamental & Médio & Superior \\
\hline Alexandria & - & 2 & - & - & - & 2 & - \\
\hline Amazônia & - & - & - & 1 & - & - & 1 \\
\hline Ciência \& Educação & - & 1 & 1 & 1 & - & 1 & 2 \\
\hline Ensaio & - & 2 & - & - & - & 2 & - \\
\hline Enseñanza* & 6 & 9 & 15 & 10 & 7 & 18 & 17 \\
\hline Eenci & - & - & 1 & 2 & 1 & - & 2 \\
\hline Góndola & 2 & - & - & 1 & 1 & 1 & 1 \\
\hline lenci & - & 1 & - & 2 & 1 & 2 & - \\
\hline RBECT & - & 1 & - & - & - & 1 & - \\
\hline RenCiMa & - & - & - & 1 & - & - & 1 \\
\hline RESA & - & 1 & - & - & - & 1 & - \\
\hline Reec* & 3 & 5 & 4 & 3 & 1 & 8 & 6 \\
\hline Revista Eureka & 2 & 2 & - & - & - & 2 & 2 \\
\hline
\end{tabular}

* Em ambas as revistas, a quantidade maior representada em relação ao número de artigos selecionados é porque alguns trabalhos focam mais de uma área e nível de ensino. 
A mesma deficiência foi observada quando se compararam os níveis educacionais, pois os artigos direcionados para o ensino fundamental possuíam uma menor porcentagem em todos os periódicos. Já em relação ao ensino médio, os artigos enfocavam tanto processos de aprendizagem dos estudantes quanto as ações didático-pedagógicas utilizadas pelos professores em sala de aula. No que tange ao ensino superior, a abordagem com viés direcionado à formação de professores se junta às duas ideias supracitadas.

Em relação ao direcionamento dos artigos, isto é, se o enfoque era uma apresentação e discussão teórica sobre algum aspecto da metacognição, ou se envolvia um estudo com participantes definidos com apresentação de resultados, prevaleceu o enfoque empírico com a participação de estudantes ou de professores na pesquisa. Em poucas oportunidades o direcionamento foi apenas teórico ou teórico e empírico (Tabela 3). Esses resultados convergem com a definição clássica de Flavell (1979) de que a metacognição se refere ao conhecimento que os sujeitos possuem sobre seus próprios processos e produtos cognitivos relacionados à sua aprendizagem. Isso significa que uma abordagem mais prática sobre as ideias de metacognição frequentemente prevalece.

Ainda na Tabela 3, expõem-se os países que mais contribuíram em publicações sobre metacognição no recorte da pesquisa. Observou-se que os pesquisadores brasileiros não possuem muitas publicações nos periódicos internacionais, ainda assim, são os que mais colaboraram com a temática, totalizando vinte e sete artigos distribuídos em quase todas as revistas analisadas. Em seguida, encontram-se autores da Argentina e Espanha, com vinte e dezessete artigos, respectivamente, concentrados nos periódicos Enseñanza de las Ciencias, Revista Electrónica de Enseñanza de las Ciencias e Revista Eureka.

Embora a pesquisa sobre metacognição ainda seja considerada incipiente, quando comparada a outras temáticas/linhas de pesquisas do Ensino de Ciências (por exemplo: experimentação, enfoque (TS), os pesquisadores e pesquisadoras brasileiras vêm contribuindo na divulgação da temática, apresentando, assim, um maior número de publicações em comparação aos autores de outros países. Não obstante, percebe-se que é importante aumentar a quantidade de publicações em periódicos internacionais, para obter maior visibilidade no campo de pesquisas em metacognição.

Tabela 3: Distribuição dos artigos selecionados frente à aplicação (teórica ou prática) e nacionalidade dos(as) autores(as).

\begin{tabular}{|c|c|c|c|c|c|c|c|c|c|c|}
\hline \multirow[b]{2}{*}{ Periódico } & \multicolumn{3}{|c|}{ Direcionamento } & \multicolumn{7}{|c|}{ Nacionalidade dos(as) autores(as) } \\
\hline & Teórico & Empírico & Ambos & Q & $\overline{E S P}$ & $P O R$ & $\overrightarrow{\mathrm{COL}}$ & CHE & $A R G$ & $\begin{array}{l}\text { MEX } \\
\text { MEX }\end{array}$ \\
\hline Alexandria & - & 2 & - & 2 & - & - & - & - & - & - \\
\hline Amazônia & - & 1 & - & 1 & - & - & - & - & - & - \\
\hline Ciência \& Educação & 1 & 2 & - & 2 & - & - & 1 & - & - & - \\
\hline Ensaio & - & 2 & - & 3 & - & - & - & - & - & - \\
\hline Enseñanza* & 7 & 26 & 5 & 3 & 13 & 3 & 6 & 2 & 12 & 2 \\
\hline Eenci & - & 2 & 1 & 3 & - & - & - & - & - & - \\
\hline Góndola & 1 & 2 & - & 2 & - & - & 1 & - & - & - \\
\hline lenci & - & 2 & 1 & 4 & - & - & - & - & - & - \\
\hline RBECT & - & 1 & - & 1 & - & - & - & - & - & - \\
\hline RenCiMa & - & 1 & - & - & - & - & - & - & 1 & - \\
\hline RESA & - & 1 & - & 1 & - & - & - & - & - & - \\
\hline REEC & 2 & 9 & 3 & 6 & 2 & 1 & - & - & 5 & - \\
\hline R. Eureka & - & 4 & - & - & 2 & - & - & - & 2 & - \\
\hline
\end{tabular}

*Um (01) artigo é de origem israelense. A quantidade total é maior que o número de artigos selecionados porque alguns trabalhos são de autores de diferentes nacionalidades. 


\section{Sistematização dos resultados em termos das abordagens} metodológicas adotadas (descritas em termos da Dimensão de Análise e suas subdivisões categoriais)

\section{Processos Metacognitivos}

Para Tovar-Gálvez (2015), os processos metacognitivos podem ser subdivididos em quatro estratégias metodológicas: Resolução de Problemas (RP), Aprendizagem por Investigação Dirigida (AID), Enfoque Ciência, Tecnologia e Sociedade (CTS) e Integração entre Didática e Metacognição (IDM).

Desta forma, consideraram-se, durante a RSL, essas quatro subdivisões para quantificar as abordagens metodológicas propostas nos artigos selecionados, assim como as ideias sobre metavisualização no Ensino de Ciências. Para Gilbert (2005), Zhang e Linn (2011) e Locatelli e Altarugio (2017), a metavisualização é uma estratégia metacognitiva referente à visualização (representaç̃̃es, símbolos, desenhos, gráficos, imagens etc.) que permite avaliar e interpretar as representações interna e externa e que pode auxiliar na aprendizagem de ciências.

Os dados da Tabela 4 apontam que a maioria dos artigos adotou propostas metodológicas do tipo IDM, seguida pela RP, Enfoque CTS, AID e Metavisualização. Tais resultados evidenciam que os autores e as autoras buscaram, ao trabalhar com metacognição, refletir sobre as estruturas conceituais iniciais dos estudantes para, em seguida, administrar o desenvolvimento dos conhecimentos a fim de realizar avaliações tanto das estratégias empregadas como do processo como um todo (TOVAR-GÁLVEZ, 2015).

Tabela 4: Distribuição dos artigos selecionados em relação às estratégias metodológicas na categoria Processos Metacognitivos (Tovar-Gálvez, 2012).

\begin{tabular}{|c|c|c|c|c|c|}
\hline \multirow{2}{*}{ Periódico } & \multicolumn{5}{|c|}{ Estratégias metodológicas utilizadas } \\
\cline { 2 - 6 } & AID $^{*}$ & Enfoque CTS & IDM $^{*}$ & Metavisual & RP \\
\hline Alexandria & - & - & 1 & - & 1 \\
\hline Amazônia & - & 1 & - & - & - \\
\hline Ciência \& Educação & - & - & 2 & - & 1 \\
\hline Ensaio & - & - & 2 & - & - \\
\hline Enseñanza & - & 1 & 24 & 1 & 5 \\
\hline Eenci & - & - & 1 & 1 & - \\
\hline Góndola & 2 & - & 1 & - & - \\
\hline lenci & - & - & 1 & - & - \\
\hline RBECT & - & - & 1 & - & - \\
\hline RenCiMa & - & 1 & - & - & - \\
\hline RESA & - & - & - & - & 1 \\
\hline Reec & - & - & 11 & - & - \\
\hline Eureka & - & - & 1 & - & 1 \\
\hline
\end{tabular}

*AID: Aprendizagem por investigação dirigida; CTS: Ciência, Tecnologia e Sociedade; IDM: Integração entre didática e metacognição; RP: Resolução de problemas. Fonte: Elaborada pelos autores.

Em uma análise mais detalhada, os dois artigos que se utilizaram da AID direcionam-se para os estudantes e buscam resolver o problema de distanciamento da Ciência com a realidade dos estudantes. No primeiro trabalho foi apresentada uma proposta de criar na 
escola o projeto "Los Semilleros de investigación" (As sementeiras de investigação), que implicava a construção de responsabilidades pelos estudantes, sobremaneira nos seus próprios processos de formação e aprendizagem científica, participando constantemente de encontros que oferecessem estratégias de apoio, motivação e superação das dificuldades (GRANADOS, 2010). A fim de consolidar o projeto, a autora apontou a indução aos estudantes de formular perguntas e propostas de atividades para estabelecer conexões com os conteúdos científicos, podendo reconstruí-los. Já no segundo artigo, os autores propuseram uma atividade investigativa na vertente de aprendizagem significativa com a temática de tabelas nutricionais. Para o desenvolvimento do tema e perspectiva de investigação, estabeleceram-se relações entre as características investigativas propostas pelo National Research Council, tais como o engajamento dos alunos, a priorização para a descoberta de evidências, explicações para elas por meio dos registros dos alunos, a conexão das explicações com o conhecimento científico e a comunicação (ZÔMPERO et al., 2014).

Segundo Tovar-Gálvez (2015), ambas as publicações buscaram, em suas metodologias, uma dinâmica de trabalhos coletivos que explicitasse os problemas observados na comunidade estudada em questão. Ao mesmo tempo, os artigos estabeleceram alternativas para melhor compreensão conceitual dos estudantes e do processo como um todo.

Nos artigos que enfatizaram o Enfoque CTS, a principal ideia abordada foi a formação inicial e continuada de professores. Gomes e Almeida (2016) investigaram o perfil metacognitivo de grupos de professores frente às habilidades de letramento científico (LC), usando para isso o modelo de Teste de Habilidades de LC. Hugo et al. (2012) se apoiaram no "Proyecto Iberoamericano sobre la Naturaleza de la Ciencia y la Tecnología", para fomentar competências metacognitivas sobre sustentabilidade. Enquanto Mellado et al. (2014) estabeleceram programas de intervenção metacognitivos e metaemocionais sobre a importância da tecnologia na sociedade e na formação de professores com atividades de autorregulação.

As abordagens supracitadas, certamente, enriquecem a formação docente, fortalecendo, assim, cada vez mais a melhoria da Educação e do Ensino de Ciências. Para Santos e Schnetzler (2010), quanto mais o professor ou a professora possuir conhecimento sobre o enfoque CTS, mais estratégias poderão desenvolver para que o cidadão possa efetivar sua participação nos problemas sociais de sua comunidade, em prol de posicionamentos e encaminhamentos de soluções.

No emprego da estratégia metodológica Metavisual, um dos artigos é direcionado para estudantes universitários, com o objetivo de melhorar a autonomia e a autorregulação sobre o conceito de ligação iônica (LOCATELLI; ALTARUGIO, 2017). As autoras propuseram aos estudantes que fizessem desenhos para representar as estruturas cristalinas de cloreto de sódio $(\mathrm{NaCl})$ e cloreto de lítio ( $\mathrm{LiCl}$ ), como uma etapa inicial da proposta, para, em seguida, aplicarem atividades metacognitivas de reflexão em grupo sobre a explicação dos desenhos produzidos e sua evolução conceitual, comparando, paralelamente, com o modelo apresentado pelas pesquisadoras durante a aula. Já no trabalho de Di Giacomo, Castelo e Galagovsky (2009), cujo foco são professores da Educação Básica, a proposta consistiu em solicitar que os professores descrevessem e explicassem, por meio de desenhos, misturas binárias e ternárias envolvendo as substâncias água, etanol e óleo, com o intuito de discutir os modelos de interações intermoleculares. 
Atividades que explorem a visualização configuram um elo importante entre a Ciência e a metacognição. Isso porque os estudantes precisam desenvolver "a metavisualização para se apropriar dos modelos usados para explicar diferentes conteúdos" e "monitorar (metacognição) seu conhecimento" (LOCATELLI; FERREIRA; ARROYO, 2010).

Das nove publicações que se utilizaram da RP como método construtivista, sete tinham como público-alvo os estudantes, sendo que cinco enfocavam problemas do tipo lápis e papel. Neste caso, o que se preconiza é um Ensino de Ciências que dê aos estudantes a oportunidade de visualizar procedimentos de solução de uma determinada situação (TOVAR-GÁLVEZ, 2015). Nesse sentido, a pesquisa apresentada por Rosa e Ghiggi (2017) intentou favorecer aos estudantes momentos de tomadas de consciência sobre seus conhecimentos, de estimulação e monitoração das ações durante a resolução de problemas. Os autores guiavam os estudantes mediante estratégias metacognitivas, como reelaboração do enunciado do problema, representação de um desenho e confrontação entre a resposta fornecida e o desenho produzido. Já Pereira e Andrade (2014, p. 4) organizaram uma atividade de "elaboração e resolução reflexivas de questões pelos estudantes", em que eles "deveriam também escrever por que ou o que os levou a elaborar tal questão, ou seja, uma justificativa para o fato de terem escolhido determinado assunto e elaborado a questão da forma como o fizeram".

Neste último artigo, os autores proporcionaram um espaço de confiança para que os próprios estudantes pudessem participar ativamente do processo de resolução do problema, o que os ensinou como enxergar a situação se preocupando com quais habilidades são necessárias para a solução (TOVAR-GÁLVEZ, 2015).

Dentre os dois artigos restantes, um procurava enfatizar a formação de professores com atividades que "buscam uma reflexão crítica sobre como tratar os conhecimentos da Física de modo a resolver problemas de adequação de metodologias e conteúdos para diferentes realidades educacionais" (CORTELA; NARDI, 2017, p. 5465). Enquanto o outro propôs um esquema teórico para desenvolver uma prova que medisse a capacidade de resolução de problemas. Aqui os autores consideraram um modelo que se apoia em nove habilidades (observação, questionamento, síntese, análise, leitura, transferência, generalização, metacognição e avaliação), a fim de construir vinte e sete indicadores que permitissem operacionalizar as variáveis desse modelo.

A categoria Integração entre Didática e Metacognição foi a que teve a maior incidência de artigos encontrados (45). Desse total, doze abarcaram a formação de professores, enquanto os demais se centraram em atividades desenvolvidas com os estudantes, divididas em: seis em Tecnologias de informação e Comunicação (TIC); cinco em leitura; três em experimentação; duas em mapas conceituais, aprendizagem cooperativa e comparação de estratégias de ensino; e uma em análise de livros didáticos, jogos, espaços não formais e revisão bibliográfica. As demais produções não tinham uma abordagem definida, sendo analisadas e avaliadas de forma mais geral.

Basicamente os artigos que abordaram a formação de professores evocam as noções que tanto professores em formação inicial quanto em formação continuada têm sobre suas práticas educativas, seus conhecimentos didáticos de conteúdo (PCK) e as questões emocionais da profissão. Nesse bojo, a maioria dos autores desenvolveu atividades de autorregulação que apresentavam elementos denotativos sobre o que os professores dizem que fazem com os elementos provenientes daquilo que realmente fazem em suas práxis pedagógicas. De acordo com Tovar-Gálvez (2015), a autorregulação como atividade 
metacognitiva na formação de professores propicia uma reflexão e avaliação de como os processos didáticos estão sendo executados em sala de aula.

Destacando os trabalhos na subárea TIC, Trentin et al. (2015, p. 274) descrevem um "processo de construção de um equipamento didático robotizado e a apresentação da proposta didático-metodológica para a abordagem dos conceitos introdutórios da cinemática no ensino médio". Nessa proposta os autores desenvolveram atividades com orientações metacognitivas e consequente monitoração, o que permitiu aos estudantes identificarem seus recursos cognitivos e a relação entre o planejamento e execução das ações utilizando o robô.

Na temática de leitura, Maturano, Mazzitelli e Macías (2006) identificaram como se dão as estratégias de avaliação e regulação da compreensão de leitura sobre um texto de Física. Como processo metacognitivo, os autores elaboraram dois testes de investigação, em que o primeiro explorava como a leitura do texto era realizada na ausência de informações científicas necessárias para a compreensão do texto (visando averiguar se os leitores seriam capazes de identificá-las), e o segundo abordava a detecção das dificuldades ou não de compreensão textual.

Rosa e Alves Filho (2014) utilizaram-se do modelo denominado Atividades Experimentais Metacognitivas (AEMc), que envolve a operação na forma de roteiros-guias, com etapas pré-experimental, experimental e pós-experimental. Para esse desenvolvimento, os autores incluíram três questionamentos metacognitivos que possibilitavam a evocação explícita dos pensamentos dos estudantes, o que representa um veículo de interlocução entre o hábito de pensar, de questionar e realizar as ações na experimentação.

Independentemente da subárea em que os artigos são abordados, o aspecto metodológico na IDM é acompanhar o desenvolvimento dos conhecimentos, assim como avaliar cada etapa da execução (TOVAR-GÁLVEZ, 2015). Isso possibilita, no que tange às questões metacognitivas, uma noção geral sobre a estratégia, permitindo, assim, avaliar o que pode ser ajustado e otimizado para outras oportunidades.

\section{Avaliação como Instrumento Metacognitivo}

Para Campanario (2000), a avaliação é uma atividade geral do Ensino de Ciências que pode fomentar o uso de estratégias metacognitivas. Nesse sentido, a análise de trabalhos que se utilizam da metacognição para avaliar a aprendizagem científica dos estudantes se torna importante porque evidencia não apenas o produto final, mas também o processo e a visão dos estudantes durante a realização das atividades.

Os dados da Tabela 5 mostram como a avaliação metacognitiva é distribuída de forma equitativa entre as três diferentes vertentes adaptadas de Campanario (2000). Cada vertente possui características específicas de desenvolvimento, contudo, todas caminham para uma autorregulação metacognitiva que resulta em uma autorreflexão dos próprios estudantes do que estão aprendendo, do que aprendem e de como aprendem.

Na estratégia de avaliação RADA, o que os autores preconizam são análises de situações que remetem a atividades que já foram realizadas anteriormente, com o intuito de dar aos estudantes a possibilidade de detectar seus avanços diante de sua aprendizagem. Um exemplo dessa avaliação é a proposta por Hinojosa e Sanmartí (2015), em que os autores trabalharam a mesma atividade (identificar os tipos de forças presentes em um desenho que expressa uma situação real do cotidiano) em distintas etapas: na primeira, as tarefas foram realizadas individualmente pelos estudantes, considerando os conhecimentos 
prévios; na segunda, foram discutidos em grupos pequenos os diferentes pontos de vista individuais para se chegar a um consenso e elaborar uma justificativa; e, por fim, na terceira etapa, foi feita uma discussão com todos os membros da sala, cujo professor compartilhou com os estudantes os resultados das análises executadas por cada grupo, para avaliar as diferentes ideias e obter as conclusões.

Tabela 5: Distribuição dos artigos selecionados em relação à categoria Uso da Avaliação como Instrumento Metacognitivo, adaptado de Campanario (2000).

\begin{tabular}{|c|c|c|c|}
\hline \multirow{2}{*}{ Periódico } & \multicolumn{3}{|c|}{ Estratégias para uma avaliação metacognitiva } \\
\cline { 2 - 4 } & $\begin{array}{c}\text { Retomada de } \\
\text { atividades e deteção } \\
\text { de avanços (RADA) }\end{array}$ & $\begin{array}{c}\text { Correções e comentários } \\
\text { do(a) professor(a) sobre os } \\
\text { erros/dificuldades (CCPE) }\end{array}$ & $\begin{array}{c}\text { Aplicação dos } \\
\text { conhecimentos em } \\
\text { diferentes situações (ACDS) }\end{array}$ \\
\hline Alexandria & - & - & - \\
\hline Amazônia & - & - & - \\
\hline $\begin{array}{c}\text { Ciência \& } \\
\text { Educação }\end{array}$ & - & - & - \\
\hline Ensaio & - & - & 2 \\
\hline Enseñanza* & 4 & 2 & - \\
\hline Eenci & - & - & 1 \\
\hline Góndola & - & 1 & - \\
\hline lenci & - & - & - \\
\hline RBECT & - & - & - \\
\hline RenCiMa & - & - & 1 \\
\hline RESA & - & - & - \\
\hline Reec & - & - & - \\
\hline Eureka & 2 & - & - \\
\hline
\end{tabular}

* Em um mesmo artigo, os autores utilizam duas estratégias para uma avaliação metacognitiva da aprendizagem.

Este tipo de atividade de avaliação metacognitiva aproxima-se do que Campanario (2000) aponta como materialização da realidade. Quando a proposta de aprendizagem envolve situações que expressam a realidade dos estudantes, eles ficam mais satisfeitos em resolvê-las, ainda mais se a atividade for planejada em etapas que admitam constantes reflexões, como a supracitada.

Já o artigo de Franco e Munford (2017) explora os CCPE enfrentados pelos estudantes. Os autores propuseram uma avaliação da aprendizagem a partir da construção discursiva de práticas de uso de evidências durante a argumentação em sala de aula. Para isso, utilizaram-se de elementos da Etnografia, ferramentas da Análise Microetnográfica do Discurso e da Teoria Pragma-Dialética da Argumentação. Durante a argumentação dos estudantes, frente aos temas científicos, originaram-se discussões entre os partícipes, bem como orientações e comentários do professor para guiar a aprendizagem dos estudantes quando os aspectos conceituais necessitavam de reformulação ou ajustes.

Avaliar por meio de ACDS é verificar o que realmente os estudantes aprenderam sobre um determinado conceito ou tema. Essa estratégia possibilita distanciar-se do molde de repetição ou reprodução de informações repassadas. Existem várias formas de desenvolver atividades com essa característica, a citar, como exemplo, o uso de analogias e suas limitações. É no "desenvolvimento de uma sequência de aulas utilizando o Modelo Didático Analógico (MDA) com o intuito de contribuir na aprendizagem dos estudantes e promover a metacognição com o auxílio do professor" que o trabalho de Santos e Infante-Malachias (2013, p. 20) enfatiza. 
As autoras propuseram uma reflexão sobre a estrutura da Terra elaborando uma sequência didática analógica com a estrutura de um abacate, com as seguintes perguntas: "como seria o abacate se: tivesse menos polpa ou se não tivesse a casca? E se o caroço fosse muito grande ou a casca fosse muito fina? E se a polpa fosse muito dura ou não existisse o caroço?" (SANTOS; INFANTE-MALACHIAS, 2013, p. 23). As primeiras aulas serviram para discussão dessas perguntas e descrição das características do abacate, que foram organizadas em uma tabela para se chegar a um consenso com a turma. Nas demais aulas, as autoras trabalharam a formação do universo, a estrutura terrestre, a constituição da Terra e a ideia de deriva continental, para em seguida alvitrar a atividade final e individual de "relacionar a estrutura da Terra com a estrutura do abacate explicando cada uma dessas relações por escrito, momento que corresponde à correlação conceitual" e o momento relacionado à metacognição, no qual os alunos refletem e tomam consciência sobre o que aprenderam e tentam explicar as relações e os processos utilizados para preparar a analogia (SANTOS; INFANTE-MALACHIAS, 2013, p. 23).

Para Francisco Junior (2010, p. 70), "o pensamento analógico faz-se necessário para compreender fenômenos não observáveis", o que foi exatamente a proposta no artigo supracitado a respeito da estrutura da Terra. Por mais que a Terra (local onde vivemos) seja um objeto concreto, o conhecimento da sua estrutura é um fenômeno não observado pelos estudantes. Ademais, a atividade proporcionou a aprendizagem por meio da comparação de situações diferentes, potencializando "competências cognitivas tais como percepção, imaginação, criatividade, memória, resolução de problemas além do desenvolvimento conceitual" (FRANCISCO JUNIOR, 2010, p. 77).

\section{Considerações Finais}

O levantamento dos dados por meio de uma Revisão Sistemática da Literatura (RSL) e, posteriormente, a análise das diferentes estratégias metacognitivas utilizadas nos artigos (aspectos metodológicos e avaliativos) nos principais periódicos voltados para o Ensino de Ciências revelaram tanto a importância do tema metacognição no processo de ensino e aprendizagem como a necessidade de maiores contribuições e aprofundamentos.

Em relação ao processo de ensino e aprendizagem, foi observado que prevaleceram as abordagens metodológicas que buscam a integração entre os aspectos didáticos e os metacognitivos, no intuito de valorizar o desenvolvimento das atividades, sua execução, seu monitoramento e avaliação do processo como um todo. Em termos de uso da metacognição como instrumento avaliativo, apesar da menor ocorrência, os trabalhos foram mais bem distribuídos nas três categorias apresentadas para avaliar o aprendizado em si do conteúdo científico.

Entretanto, quando se pensa quantitativamente sobre a metacognição, considerando o número de revistas analisadas, seu início de publicação, periodicidade e qualidade/relevância, a temática está aquém se comparada com outras linhas de pesquisa, como formação de professores, ludicidade e Ensino das Ciências, experimentação, Tecnologias de Informação e Comunicação (TIC), Enfoque CTS, modelos e analogias, etc. Esses resultados acenam para dois pontos: primeiro a baixa quantidade de linhas de pesquisa sobre metacognição tanto no Brasil e América Latina quanto na Espanha e Portugal; segundo a dificuldade de identificar elementos metacognitivos em atividades desenvolvidas em sala de aula, pois alguns artigos até possuem características que se 
aproximam da metacognição, porém, os próprios autores, muitas vezes, não a reconhecem em suas publicações, denotando, assim, a falta de conhecimento sobre a temática em questão e sua importância para o processo de ensino e aprendizagem das ciências naturais.

Tendo em vista tais considerações, os resultados apresentados neste artigo podem de certa forma desencadear, em grupos de pesquisa em Ensino de Ciências, o interesse pelo campo de investigação sobre metacognição para intensificar suas contribuições para a área de Educação em Ciências. Isso é importante porque, conceitualmente, a metacognição é relevante não apenas para entender os processos e os produtos cognitivos dos estudantes e professores(as), mas também para que os próprios sujeitos das ações pedagógicas se avaliem e se autorregulem durante o desenvolvimento das atividades em sala de aula.

\section{Referências}

BARDIN, L. Análise de conteúdo. São Paulo: Edições 70, 2011.

CAMPANARIO, J. M. El desarrollo de la metacognición en el aprendizaje de las ciencias: estrategias para el profesor y actividades orientadas al alumno. Enseñanza de las Ciencias, v. 18, n. 3, p. 369-380, 2000.

CORTELA, B. S. C.; NARDI, R. O ensino em didática da ciência na formação inicial de professores de Física: o desafio da simetria invertida. Enseñanza de las Ciencias, v. extra, p. 5463-5468, 2017.

DI GIACOMO, M.; CASTELO, V.; GALAGOVSKY, L. De la mente al discurso: ¿qué comunicamos los docentes cuando utilizamos dibujos? Enseñanza de las Ciencias, v. extra, p. 192-197, 2009.

FLAVELL, J. H. Metacognition and Cognitive Monitoring - A New Area of CognitiveDevelopmental Inquiry. American Psychologist, v. 34, n. 10, p. 906-911, 1979.

FRANCISCO JUNIOR, W. E. Analogias e situações problematizadoras em aulas de ciências. São Carlos: Pedro \& João Editores, 2010.

FRANCO, L. G.; MUNFORD, D. Quando as crianças argumentam: a construção discursiva do uso de evidências em aulas investigativas de ciências. Investigações em Ensino de Ciências, v. 22, n. 3, p. 102-124, 2017.

GALVÃO, T. F.; PEREIRA, M. G. Revisões sistemáticas da literatura: passos para sua elaboração. Epidemiologia e Serviços de Saúde, v. 23, n. 1, 183-184, 2014.

GILBERT, J. K. (2005). Visualization, a metacognitive skill in science and science education. In GILBERT, J.K. (Ed.), Visualization in science education. The Netherlands: Springer, 9-27.

GLASER, R. Learning theory and instruction. En: G. D'Ydewalle, P. Eelen y B. Bertelson (Eds.). International perspectives on psychological science. (Vol. 2) NJ: Erlbaum, 1994.

GOMES, A. S. A.; ALMEIDA, A. C. P. C. Letramento científico e consciência metacognitiva de grupos de professores em formação inicial e continuada: um estudo exploratório. Amazônia: Revista de Educação em Ciências e Matemática, v. 12, n. 24, p. 53-72, 2016.

GRANADOS, L. L. A. Creando semilleros de investigación en la escuela. Góndola: Enseñanza y Aprendizaje de las Ciencias, v. 5, n. 1, p. 3-10, 2010. 
HINOJOSA, J.; SANMARTÍ, N. La autorregulación metacognitiva como medio para facilitar la transferencia en mecánica. Revista Eureka sobre Enseñanza y Divulgación de las Ciencias, v. 12, n. 2, p. 249-263, 2015.

HUGO, D. V.; OLAVEGOGEASOECHEA, M.; OLEA, P.; ÁVILA, S.; FARIAS, N. Luces y sombras de la tecnología. Revista de Ensino de Ciências e Matemática, p. 70-79, 2012.

JOU, G. I.; SPERB, T. M. A Metacognição como Estratégia Reguladora da Aprendizagem. Psicologia: Reflexão e Crítica, v. 19, n. 2, 177-185, 2006.

LEITE, E. A.; DARSIE, M. M. P. Implicações da metacognição no processo de aprendizagem da matemática. Revista Eletrônica de Educação, v. 5, n. 2, nov. 2011.

LOCATELLI, S. W. Tópicos de Metacognição - para aprender e ensinar melhor. Curitiba: Appris, 2014.

LOCATELLI, S. W.; ALTARUGIO, M. H. Estratégia metacognitiva para repensar e reconhecer conceitos em ligação iônica. Experiências em Ensino de Ciências, v. 12, n. 6, p. 138-152, 2017.

LOCATELLI, S. W.; FERREIRA, C.; ARROYO, A. Metavisualização: uma habilidade importante no ensino de Química. Anais do XV Encontro Nacional de Ensino de Química: Brasília/DF, 2010.

MATURANO, C.; MAZZITELLI, C.; MACÍAS, A. ¿Cómo los estudiantes regulan la comprensión cuando leen un texto instructivo con dificultades? Revista Electrónica de Enseñanza de las Ciencias, v. 5, n. 2, p. 235-246, 2006.

MELLADO, $\vee$. et al. Las emociones en la enseñanza de las ciencias. Enseñanza de las Ciencias, v. 3, n. 32, p. 11-36, 2014.

MORENO, J. C.; MOYA, A.; LARGUERO, J. M. C.; GUTIÉRREZ, J. O. La metacognición y el aprendizaje de las ciencias. In: HERNANDEZ, E. B.; BUENO, A. J. P. (Orgs.). Investigación e innovación en la enseñanza de las ciencias. Espanha: DM Editores, p. 36-44, 1998.

MOTTA, A. G. O. Continuum cognição-metacognição nas estratégias bottom-up empregadas na compreensão textual em L2. Dissertação de mestrado. Universidade de Santa Cruz do Sul. Santa Cruz do Sul, 2007.

PEREIRA, M. M.; ANDRADE, V. A. Elaboração e resolução de questões pelos estudantes: um estudo de caso acerca de aspectos cognitivos e metacognitivos. Revista Ensino, Saúde e Ambiente, v. 7, n. 1, edição especial, p. 1-13, 2014.

PORTILHO, E. M. L.; DREHER, S. A. S. Categorias metacognitivas como subsídio à prática pedagógica. Educação e Pesquisa, v. 38, n. 1, 181-196, 2012.

ROSA, C. T. W.; GHIGGI, C. M. Monitoramento e controle metacognitivo na resolução de problemas em Física: análise de um estudo comparativo. Alexandria, v. 10, n. 2, p. 105-125, 2017.

ROSA, C. W.; ALVES FILHO, J. de P. Estudo da viabilidade de uma proposta didática metacognitiva para as atividades experimentais em Física. Ciência \& Educação, v. 20, n. 1, p. 61-81, 2014.

SALVADOR, A. D. Métodos e técnicas de pesquisa bibliográfica. Porto Alegre: Sulina, 1986. 
SANTOS, D. B.; INFANTE-MALACHIAS, M. E. Utilização do modelo didático analógico (MDA) no ensino de ciências: uma experiência sobre a estrutura da Terra. Experiências em Ensino de Ciências, v. 8, n. 2, p. 20-27, 2013.

SANTOS, W. L. P.; SCHNETZLER, R. P. Educação em química - compromissos com a cidadania. 4. ed. ljuí: Unijuí, 2010.

STERNBERG, R. J. Psicologia cognitiva. Porto Alegre: Artmed, 2000.

TOVAR-GÁLVEZ, J. C. Metacognición y Didáctica de las Ciencias. Saarbrücken: Editorial Académica Espanhola (EAE), 2012.

TRENTIN, M. A. S.; ROSA, C. T. W.; ROSA, A. B.; TEIXEIRA, A. C. Robótica educativa livre no ensino de Física: da construção do robô à elaboração da proposta didática de orientação metacognitiva. Revista Brasileira de Ensino de Ciências e Tecnologia, v. 8, n. 3, p. 274-292, 2015.

ZHANG Z. H.; LINN, M. C. Can generating representations enhance learning with dynamic visualizations? Journal of Research in Science Teaching, v. 48, n. 10, p. 1177-1198, 2011.

ZOMPERO, A. F.; SAMPAIO, H. R.; LABURÚ, C. E.; GONÇALVES, C. E. S. Atividade investigativa na perspectiva da aprendizagem significativa: uma aplicação no ensino fundamental com a utilização de tabelas nutricionais. Góndola: Enseñanza y Aprendizaje de las Ciencias, v. 9, n. 2, 10-21, 2014. 